\title{
Objectively determined physical activity levels of primary school children in south-west Germany
}

\author{
Sarah Kettner ${ }^{1 *}$, Susanne Kobel ${ }^{1}$, Nanette Fischbach ${ }^{1}$, Clemens Drenowatz $^{1}$, Jens Dreyhaupt ${ }^{2}$, Tamara Wirt ${ }^{1}$,
} Benjamin Koch ${ }^{1}$ and Jürgen Michael Steinacker ${ }^{1}$

\begin{abstract}
Background: Only a small proportion of children and adolescents meet current recommendations of at least 60 min of moderate to vigorous physical activity (MVPA) daily. Most of the available data, however, relies on subjective reports; there is limited objective data on physical activity (PA) levels in German primary school children. The purpose of this study, therefore, was to accurately determine how much time children spend undertaking different intensities of PA and being sedentary during weekdays and weekend using objective assessment tools. Gender-specific and age-related differences were examined along with differences between normal weight and overweight/obese children.
\end{abstract}

Methods: Children's height and weight were measured according to standard procedures and objective PA measurements were determined in a sub-cohort of 384 primary school children (20\% of the whole cohort), participating in a large school-based intervention study in south-west Germany $(n=1947)$. Baseline data collection occurred on six consecutive days, including weekend days, using multi-sensor accelerometry (Actiheart, CamNtech Ltd., Cambridge UK). 318 children ( $7.1 \pm 0.6$ years, male: 50\%, first grade: $51 \%)$ provided data for at least 3 days including one weekend day. According to the amount of energy expended, defined as metabolic equivalents (METs), different activity intensities were categorised as follows: sedentary < 1.5 METs; light = 1.5-3.0 METs; moderate $=3.0-6.0$ METs, and vigorous $>6.0$ METs.

Results: Average wear time was $1403 \pm 94 \mathrm{~min} /$ day. Children spent $808 \pm 97 \mathrm{~min} /$ day being sedentary; $497 \pm 72 \mathrm{~min} /$ day in light; $128 \pm 54 \mathrm{~min} /$ day in moderate, and $8 \pm 10 \mathrm{~min} /$ day in vigorous intensity. $48 \%$ of children met the current MVPA guidelines. MVPA was significantly higher on weekdays compared to weekend days (144 \pm 66 vs. $113 \pm 66 \mathrm{~min} /$ day; $\mathrm{p}<0.001)$. Furthermore, boys displayed higher MVPA levels compared to girls $(164 \pm 57$ vs. $106 \pm 50 \mathrm{~min} /$ day; $p<0.001)$.

Conclusion: Measured objectively, less than half of primary school children in the study met current PA recommendations, emphasising the necessity for early intervention to promote PA. Consistent with previous research, PA levels were higher in boys and during weekdays. These results indicate that PA levels of girls should especially be promoted in primary schools and that parents should be more involved in interventions to improve PA, particularly during weekends.

Keywords: Inactivity, Energy expenditure, Youth, Body weight, Exercise

\footnotetext{
* Correspondence: sarah.kettner@uni-ulm.de

'Sports- and Rehabilitation-Medicine, Research Group "Join the Healthy Boat - Primary School", Ulm University, Frauensteige 6 - House 58 / 33, 89075 Ulm, Germany

Full list of author information is available at the end of the article
} 


\section{Background}

It is well documented that sufficient physical activity (PA) is essential for childhood development and is highly relevant to health [1]. It is assumed that PA levels are established at a young age $[2,3]$ and that an active lifestyle during childhood facilitates sufficient PA during adulthood [4-6]. Insufficient PA has been associated with an increased risk of obesity [1,7] and associated comorbidities such as metabolic or cardiovascular diseases $[8,9]$. Besides biological reasons, declining PA levels have been predominantly attributed to social and cultural changes. In particular, current lifestyles promote sedentary routines due to a reduction in active transport, physical education at schools or organised sports $[4,10]$.

The World Health Organisation recommends that children should engage in at least $60 \mathrm{~min}$ of moderate physical activity (moderate to vigorous physical activity (MVPA)) per day [11].

Based on self-report, it has been suggested that approximately $30-40 \%$ of children and adolescents between 2 and 18 years of age meet these recommendations [12]. In the German Health Interview and Examination Survey for Children and Adolescents (KiGGS), less than $20 \%$ of children aged 7-10 years reported sufficient MVPA. Furthermore, one in four children did not engage in regular sport and one in eight children did not participate in any sport $[13,14]$. In German adolescents, only $14 \%$ of girls and $20 \%$ of boys undertook at least 60 min of MVPA [15]. However, the accuracy of such subjective reports on PA in children especially remains questionable, due to their sporadic and unstructured behavioural patterns [16]. Consequently, pedometers or accelerometers have been introduced in order to accurately detect and measure children's PA patterns [12]. Data from these studies would suggest that in children across different European countries only $4.6 \%$ of girls and $16.8 \%$ of boys aged 10-12 years meet current PA recommendations [17]. In Germany, data regarding objectively measured PA is limited, particularly in primary school children in first and second grade.

The purpose of the present study, therefore, was to objectively determine the amount of children's PA and sedentary time with a multi-sensor accelerometer. In addition, differences in PA patterns between weekdays and weekends together with differences in PA between boys and girls were examined. Furthermore, age-related differences in PA and variances between normal weight and overweight/obese children were examined.

\section{Methods}

\section{Study population}

Baseline data of a sub-sample of the Baden-Württemberg study, which evaluated a large school-based health promotion programme "Join the Healthy Boat - Primary
School" in south-west Germany, was used. Study design and protocol of the Baden-Württemberg study has been described in detail elsewhere [18]. Parental consent and child assent were obtained prior to data collection. The study was approved by the institutional ethics committee of Ulm University and is registered at the German Clinical Trials 127 Register (DRKS00000494).

Data collection occurred between September and November 2010, in a sample of 1947 children. For logistical reasons (distances between schools and scope of measurements of the Baden-Württemberg study) objective PA assessments were only carried out in the region of Ulm. A total number of 703 children in 32 schools and 56 classes (first and second grade) were available in this area. $62 \%$ of parents $(n=433)$ provided written informed consent for their children to wear the multi-sensor accelerometer for six consecutive days.

In order to be eligible to participate, a minimum of 5 children from each school were required to provide consent. The maximum number of parental consents obtained was 22 children. Due to children being absent from school on the day of the visit or refusing to take part in measurement of PA, a sub-sample of 384 children $(20 \%$ of the whole cohort; $\mathrm{n}=1947)$ was assessed. $83 \%$ of children ( $\mathrm{n}=318 ; 7.1 \pm 0.6$ years; boys: $50 \%$; first grade: $51 \%$ ) provided valid data of at least 3 days with more than 10 hours of daily wear time (Figure 1 ).

\section{Anthropometric measurements}

Height and weight were measured according to standard procedures with children wearing only underwear and no shoes. Height was measured to the nearest $0.1 \mathrm{~cm}$ with a stadiometer (Seca 213, weighing and measurement systems, Hamburg, Germany) and weight was measured to the nearest $0.05 \mathrm{~kg}$, using calibrated electronic scales (Seca 862, weighing and measurement systems, Hamburg, Germany). Body mass index (BMI) was calculated $\left(\mathrm{kg} / \mathrm{m}^{2}\right)$ and converted to BMI percentiles (BMIPCT) using German reference values [19]. Weight status has been subsequently classified as overweight/ obese ( $\geq 90$ percentile), normal weight ( $\geq 10$ to $<90$ percentile), and underweight $(<10$ percentile). In addition, weight status was calculated according to international reference values [20] with corresponding results shown as Table 1.

\section{Physical activity measurements}

A multi-sensor accelerometer (Actiheart, CamNtech Ltd., Cambridge UK) was fitted to each child's chest using two electrodes and additionally protected with eudermic plasters. The Actiheart is a lightweight $(8 \mathrm{~g})$ multi-sensor accelerometer combining measurements of acceleration and heart rate (HR) to determine PA [21]. The participants were asked to wear the multi-sensor device 


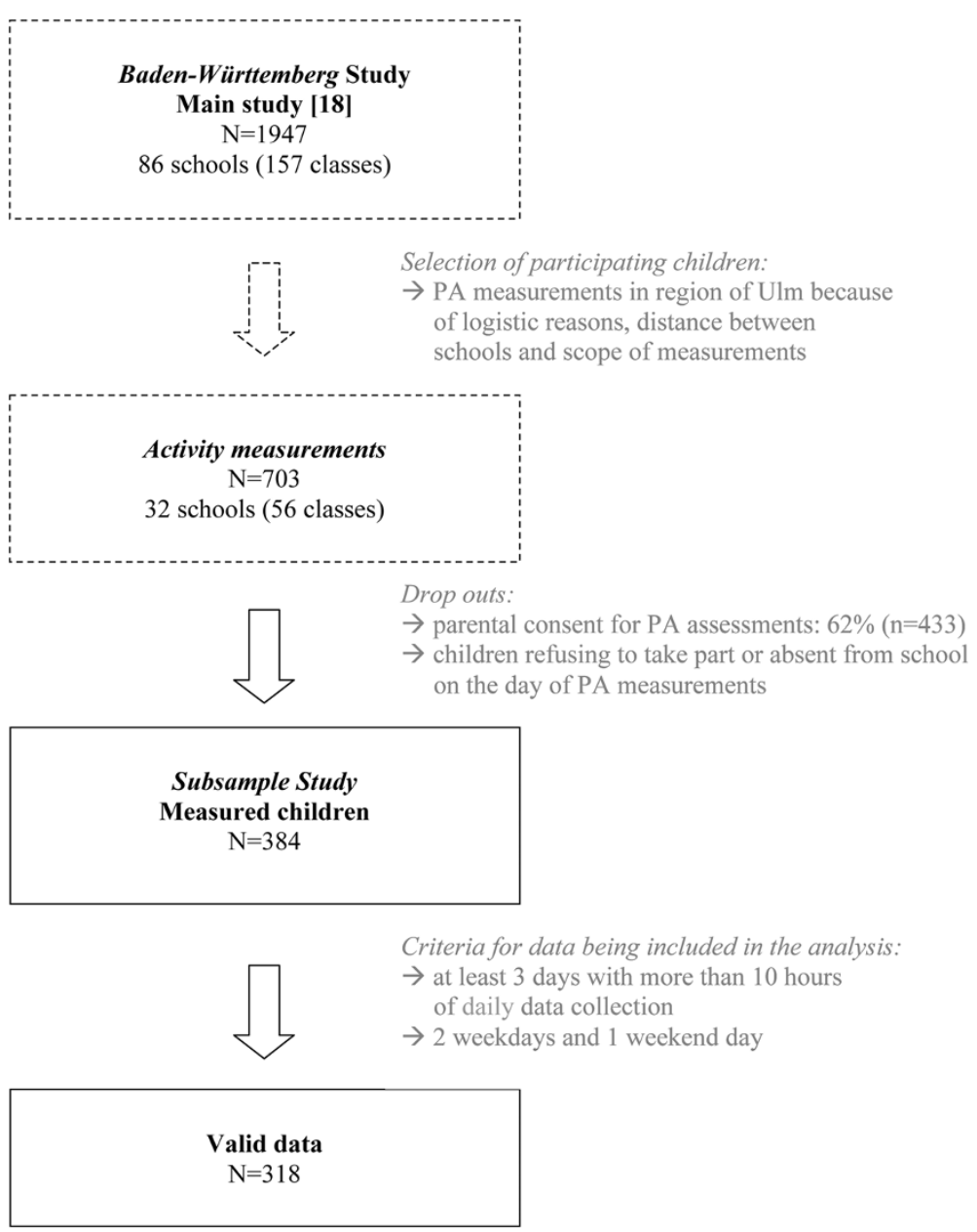

Figure 1 Flow-chart of activity measurement procedure for Baden-Württemberg study.

for six consecutive days (à $24 \mathrm{~h}$ ) including two weekend days. The recording interval was set to 15 sec. Parents were informed about the use and care of the tool in case the sensor was disconnected from the electrodes.

Energy expenditure, defined as metabolic equivalents (METs), was estimated via the captive Actiheart software (Version 4.0.73) [22], using a branched model approach previously validated in children [23]. Age, height, body weight and gender were used in addition to heart rate and accelerometry data to estimate the MET level. Data was classified as sedentary (< $1.5 \mathrm{METs})$; light (1.5-3.0 METs); moderate (3.0-6.0 METs), and vigorous (> 6.0 METs) [24].

To be included in the analysis, at least 3 days with more than 10 hours of daily data collection, including 2 weekdays and 1 weekend day, were required. Trost et al.

Table 1 Descriptive characteristics of total sample, boys and girls

\begin{tabular}{lccc}
\hline & $\begin{array}{c}\text { Total sample } \\
{[\mathbf{n = 3 1 8}]}\end{array}$ & $\begin{array}{c}\text { Boys } \\
{[\mathbf{n = 1 5 9 ]}}\end{array}$ & $\begin{array}{c}\text { Girls } \\
\text { [n= 159] }\end{array}$ \\
\hline Age [yrs] & $7.1 \pm 0.6[5.5-9.9]$ & $7.1 \pm 0.6[6.0-9.9]$ & $7.1 \pm 0.6[5.5-9.3]$ \\
Height [cm] & $123.7 \pm 6.1[104.6-141.2]$ & $124.0 \pm 6.2[106.4-141.2]$ & $123.4 \pm 6.1[104.6-139.3]$ \\
Weight [kg] & $24.6 \pm 4.9[15.60-47.00]$ & $25.0 \pm 5.0[15.60-47.00]$ & $24.2 \pm 4.7[16.65-45.50]$ \\
Weight status [\%] & & & \\
International ref [20] & 9.5 & 10.1 & 3.9 \\
- Overweight & 3.5 & 3.1 & 3.8 \\
- Obese & & & \\
\hline
\end{tabular}

Values are mean \pm SD and percentage of overweight/obese children [20]. 
(2000) indicate that 4 and 5 days of recording physical activity would be necessary to obtain a reliability of 0.80 in children [25]. Furthermore, to extrapolate the available days to a full week, a ratio of 5:2 for weekdays and weekend days was used. First and last recording days were excluded from analysis. In order to meet current PA guidelines, $60 \mathrm{~min}$ of MVPA was required for every single day of PA assessment.

In addition, PA was collected via parental questionnaire, whether the children engage in any sporting activities or participate in sports clubs. Parents were also asked on how many days per week their child achieves at least $60 \mathrm{~min}$ of MVPA.

\section{Socio-demographic data}

Socio-demographic data was assessed via a parental questionnaire. Parental education was classified according to CASMIN [26], which was determined by the highest level of two parents or the level of a single parent. Due to the low number of cases at primary education level, primary and secondary education levels were combined into a single group (defined as low education level) while tertiary education level was considered to be high education level. Where there was at least one parent born abroad or speaking a foreign language during the first years of a child's life, background was defined as "migration".

\section{Statistical analysis}

Descriptive statistics were calculated (mean values and standard deviations). Group differences between means were analysed with independent $\mathrm{t}$-test and $\mathrm{chi}^{2}$-test was used to analyse group differences with categorical variables, respectively. Repeated measures ANOVA was used to examine differences between weekdays and weekend days. Furthermore, group differences between boys and girls were examined using ANCOVA adjusting for age and BMIPCT. Similarly, differences between first and second grade children were analysed, adjusting for gender and BMIPCT. To determine differences by weight status
ANCOVA, adjusting for gender and age has been used. Underweight children $(n=26 ; 8 \%)$ were excluded from analysis. Statistical analyses were performed using PASW 19.0 (Predictive Analytics Software, SPSS Inc, Chicago, IL, US), with a level of significance set at $\mathrm{p} \leq 0.05$.

\section{Results}

Between the sub-sample $(\mathrm{n}=384)$ and the total study population there were no differences in descriptive characteristics (sex, age, height, body weight, BMI percentiles (BMIPCT), sports participation, migration background and parent education). Children from the 32 schools and 56 classes in the region of Ulm providing consent for the objective measurement did not differ from those refusing to participate in the objective measurement either. Concerning subjectively assessed PA behaviour via parental questionnaire no differences were found between the sub-sample and the total study population.

Descriptive characteristics are shown in Table 2. There were no differences in anthropometric characteristics between boys and girls. Almost $11 \%(n=34)$ of the children were classified as overweight or obese, based on German reference values. The prevalence was slightly higher using international cut-off points [20] (Table 1). Average recording time was $1403 \pm 94 \mathrm{~min} /$ day. There were no differences in wearing time between boys and girls, first and second grade children nor between normal weight and overweight children. Table 3 displays the time spent in different activity intensities and the percentage of children achieving MVPA guidelines. Less than half of the children (48\%) met current PA recommendations. Including sleep, most of the time was spent being sedentary $(56.1 \%)$ with roughly one third in light activities (34.5\%). Only $9.4 \%$ of the time accounted for MVPA, mainly in moderate intensity (8.9\%).

Girls spent more time in sedentary activities (841 \pm $97 \mathrm{~min} /$ day vs. $775 \pm 86 \mathrm{~min} /$ day for girls and boys, respectively; $\mathrm{p}<0.001)$, while boys were more active than girls in MVPA $(164 \pm 57 \mathrm{~min} /$ day vs. $106 \pm 50 \mathrm{~min} /$ day, respectively; $\mathrm{p}<0.001)$. Consequently, more boys met PA

Table 2 Descriptive characteristics of total sample, boys and girls

\begin{tabular}{|c|c|c|c|}
\hline & $\begin{array}{c}\text { Total sample } \\
{[n=318]}\end{array}$ & $\begin{array}{c}\text { Boys } \\
{[n=159]}\end{array}$ & $\begin{array}{c}\text { Girls } \\
{[n=159]}\end{array}$ \\
\hline Age [yrs] & $7.1 \pm 0.6[5.5-9.9]$ & $7.1 \pm 0.6[6.0-9.9]$ & $7.1 \pm 0.6[5.5-9.3]$ \\
\hline Height $[\mathrm{cm}]$ & $123.7 \pm 6.1[104.6-141.2]$ & $124.0 \pm 6.2[106.4-141.2]$ & $123.4 \pm 6.1[104.6-139.3]$ \\
\hline Weight [kg] & $24.6 \pm 4.9[15.60-47.00]$ & $25.0 \pm 5.0[15.60-47.00]$ & $24.2 \pm 4.7[16.65-45.50]$ \\
\hline BMIPCT & $48.1 \pm 28.0[2-100]$ & $50.4 \pm 27.2[2-100]$ & $45.7 \pm 28.6[2-100]$ \\
\hline \multicolumn{4}{|c|}{ Weight status [\%] } \\
\hline - Overweight & 6.3 & 6.3 & 6.3 \\
\hline - Obese & 4.4 & 5.0 & 3.8 \\
\hline
\end{tabular}

Values are mean \pm SD and percentage of overweight/obese children [20]. 
Table 3 Time spent in different intensities and percentage of children meeting PA guidelines

\begin{tabular}{|c|c|c|c|c|}
\hline & $\begin{array}{c}\text { Total sample } \\
{[n=318]}\end{array}$ & $\begin{array}{c}\text { Boys } \\
{[n=159]}\end{array}$ & $\begin{array}{c}\text { Girls } \\
{[n=159]}\end{array}$ & $p$-value \\
\hline \multicolumn{5}{|l|}{ Total week [min/day] } \\
\hline Sedentary PA & $808 \pm 97$ & $775 \pm 86$ & $841 \pm 97$ & $\mathrm{p}<0.001$ \\
\hline Light PA & $497 \pm 72$ & $501 \pm 71$ & $492 \pm 73$ & $p=0.179$ \\
\hline Moderate PA & $128 \pm 54$ & $152 \pm 51$ & $103 \pm 46$ & $\mathrm{p}<0.001$ \\
\hline Vigorous PA & $8 \pm 10$ & $12 \pm 11$ & $3 \pm 6$ & $\mathrm{p}<0.001$ \\
\hline MVPA & $135 \pm 61$ & $164 \pm 57$ & $106 \pm 50$ & $\mathrm{p}<0.001$ \\
\hline \multicolumn{5}{|l|}{ Weekend [min/day] } \\
\hline Sedentary PA & $851 \pm 110$ & $820 \pm 102$ & $883 \pm 108$ & $\mathrm{p}<0.001$ \\
\hline Light PA & $476 \pm 80$ & $481 \pm 78$ & $470 \pm 82$ & $p=0.154$ \\
\hline Moderate PA & $108 \pm 62$ & $131 \pm 60$ & $85 \pm 54$ & $\mathrm{p}<0.001$ \\
\hline Vigorous PA & $5 \pm 8$ & $8 \pm 9$ & $2 \pm 4$ & $\mathrm{p}<0.001$ \\
\hline MVPA & $113 \pm 66$ & $139 \pm 65$ & $87 \pm 56$ & $\mathrm{p}<0.001$ \\
\hline \multicolumn{5}{|l|}{ Weekdays [min/day] } \\
\hline Sedentary PA & $791 \pm 104$ & $757 \pm 92$ & $825 \pm 105$ & $\mathrm{p}<0.001$ \\
\hline Light PA & $505 \pm 79$ & $509 \pm 78$ & $501 \pm 80$ & $p=0.258$ \\
\hline Moderate PA & $135 \pm 58$ & $160 \pm 56$ & $111 \pm 50$ & $\mathrm{p}<0.001$ \\
\hline Vigorous PA & $9 \pm 12$ & $14 \pm 13$ & $3 \pm 8$ & $\mathrm{p}<0.001$ \\
\hline MVPA & $144 \pm 66$ & $174 \pm 64$ & $114 \pm 55$ & $\mathrm{p}<0.001$ \\
\hline \multicolumn{5}{|l|}{$\geq 60$ min MVPA per day } \\
\hline Meeting recommendations & $48 \%$ & $68 \%$ & $28 \%$ & \\
\hline
\end{tabular}

Values are mean \pm SD. P-value based on ANCOVA, adjusted for age and BMIPCT.

Values are mean \pm SD and percentage of overweight/obese children [20].

recommendations compared to girls (68\% vs. 28\%). Moreover, there was a difference between activity behaviour during the week and weekend. Higher PA levels were observed during the week $\left[\mathrm{F}_{\mathrm{MVPA}}(1,317)=91.6 ; \mathrm{p}<0.001\right]$ whilst more time was spent being sedentary during the weekend $\left[\mathrm{F}_{\mathrm{SED}}(1,317)=134.3 ; \mathrm{p}<0.001\right]$. Children who recently started school (first grade) spent more time in light intensity than children in second grade (506 \pm 73 vs. $488 \pm 70$ min per day, respectively; $\mathrm{p}=0.024$ ), whereas second grade children spent more time undertaking moderate activities, resulting in more time spent in MVPA (Figure 2). No difference was found for sedentary activities between first and second grade children.

In addition, there was no difference in sedentary time between normal weight and overweight/obese children but normal weight children spent more time doing light activities ( $498 \pm 68$ vs. $467 \pm 66$ min per day, respectively; $\mathrm{p}=0.023$ ) than their overweight/obese counterparts. However, children categorised as overweight or obese spent more time in moderate and vigorous intensities than normal weight children, resulting in higher MVPA levels (Figure 3). Similar results occurred when using IOTF (International Obesity Task Force) cut-off points for overweight and obesity (Table 4). Interactions between gender and weight status as well as interactions between gender and first and second grade children were not significant.

\section{Discussion}

The results of this study indicate that school children from south-west Germany spend over half of their day being sedentary (56.1\%) and one third of their day undertaking light activities (34.5\%). Less than half of these children are meeting the current PA recommendations of at least $60 \mathrm{~min}$ MVPA per day.

This reported percentage of children meeting current PA recommendations is comparable to Spanish children [27] while it is slightly higher than previously reported PA levels of 7-10-year-old German children, based on self-reported PA [13]. Riddoch et al. (2004), conversely, reported that $80 \%$ of 9 -year-old children from a large Norwegian sample met current PA guidelines [28]. Overall, these results emphasise that the proportion of children meeting current PA recommendations varies enormously and differs between countries. Beets et al. (2011) reported a span of between $7 \%$ and $96 \%$ in preschool children complying with PA recommendations [29]. These differences may be at least partially be explained by variations in the interpretation of guidelines, alternative methodologies and the utilisation of different 


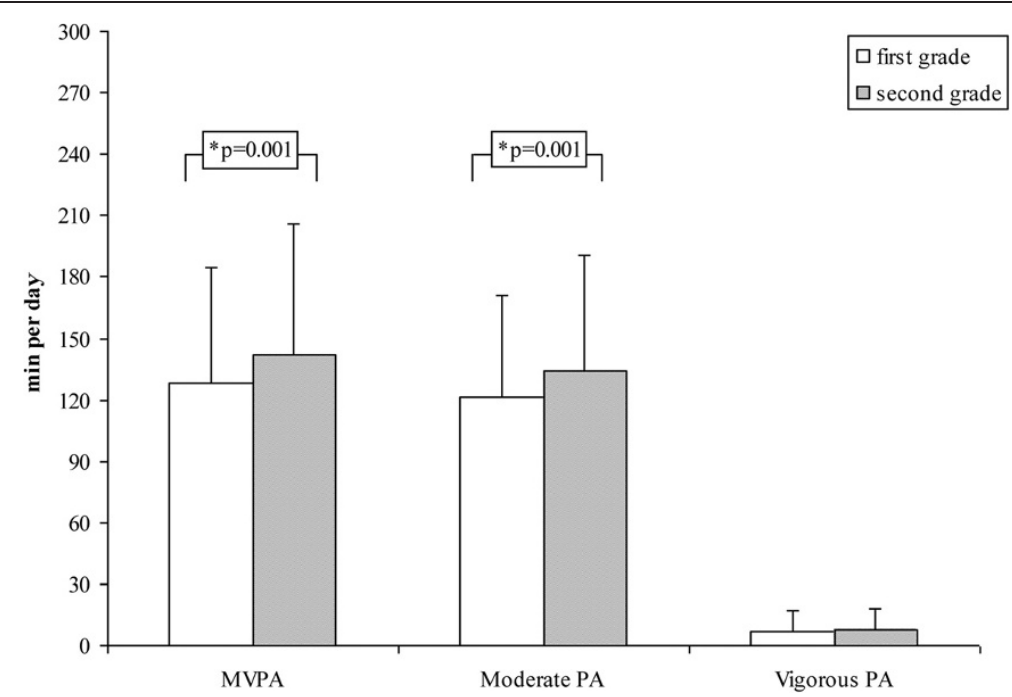

Figure 2 Different PA levels of first grade and second grade children; values are mean \pm SD. P-value based on ANCOVA, adjusted for gender and BMIPCT.

cut-off points to determine MVPA when using accelerometry [12].

In the present study, children were less active during the weekend than during the week, despite weekend days offering children more available time for physical activities, such as playing outdoors. Similar results have been reported in German pre-school children aged 3-6 years and in 9 and 15 year old European and Canadian children aged 10-15 years [30-32].

The above findings are particularly relevant for the design of effective intervention programmes, as they indicate a need for a stronger involvement of parents in health promotion programmes. Sallis et al. (1991) argue that parents have an essential impact on their child's PA [16] and several studies have indicated that children of more active parents are also likely to be more physically active [33,34]. In addition, parental encouragement for PA has been associated with positive effects on children's PA [35]. For the promotion of PA, it is important to identify opportunities to families for being active, especially at the weekend. Furthermore, Cleland et al. (2008) emphasised the importance of time spent outdoors during the weekend as this was associated with higher MVPA in 10-12 year old children [36]. Children spending more time outdoors also displayed a lower prevalence of overweight. However, more research is needed

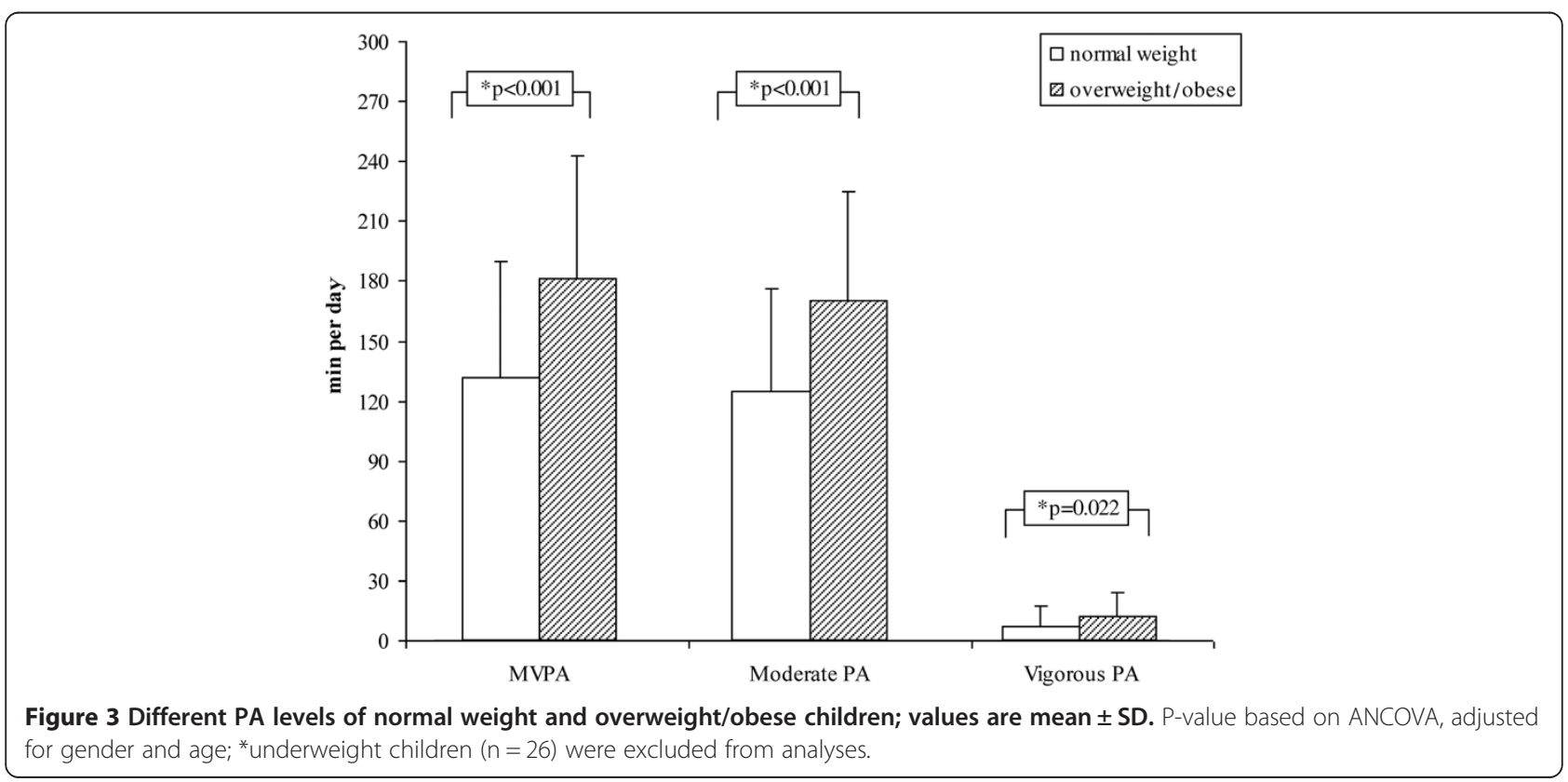


Table 4 Differences between normal weight and overweight/obese children [20] in time spent in different PA intensities and percentage of children meeting PA guidelines

\begin{tabular}{|c|c|c|c|c|}
\hline & $\begin{array}{c}\text { Total sample } \\
{[n=318]}\end{array}$ & $\begin{array}{c}\text { Normal weight } \\
\quad[n=241]\end{array}$ & $\begin{array}{l}\text { Overweight/obese } \\
{[n=41]}\end{array}$ & p-value* \\
\hline \multicolumn{5}{|l|}{ Total Week [min/day] } \\
\hline Sedentary PA & $808 \pm 97$ & $810 \pm 95$ & $793 \pm 92$ & $p=0.264$ \\
\hline Light PA & $497 \pm 72$ & $497 \pm 68$ & $471 \pm 67$ & $p=0.049$ \\
\hline Moderate PA & $128 \pm 54$ & $125 \pm 52$ & $164 \pm 55$ & $\mathrm{p}<0.001$ \\
\hline Vigorous PA & $8 \pm 10$ & $8 \pm 10$ & $11 \pm 12$ & $p=0.019$ \\
\hline MVPA & $135 \pm 61$ & $133 \pm 58$ & $176 \pm 63$ & $p<0.001$ \\
\hline \multicolumn{5}{|l|}{ Weekend [min/day] } \\
\hline Sedentary PA & $851 \pm 110$ & $856 \pm 109$ & $826 \pm 108$ & $p=0.066$ \\
\hline Light PA & $476 \pm 80$ & $474 \pm 79$ & $463 \pm 74$ & $p=0.625$ \\
\hline Moderate PA & $108 \pm 62$ & $105 \pm 61$ & $144 \pm 60$ & $p<0.001$ \\
\hline Vigorous PA & $5 \pm 8$ & $5 \pm 8$ & $7 \pm 10$ & $p=0.023$ \\
\hline MVPA & $113 \pm 66$ & $110 \pm 65$ & $151 \pm 66$ & $\mathrm{p}<0.001$ \\
\hline \multicolumn{5}{|l|}{ Weekdays [min/day] } \\
\hline Sedentary PA & $791 \pm 104$ & $791 \pm 102$ & $779 \pm 98$ & $p=0.520$ \\
\hline Light PA & $505 \pm 79$ & $507 \pm 75$ & $475 \pm 74$ & $p=0.021$ \\
\hline Moderate PA & $135 \pm 58$ & $134 \pm 55$ & $173 \pm 59$ & $\mathrm{p}<0.001$ \\
\hline Vigorous PA & $9 \pm 12$ & $9 \pm 12$ & $13 \pm 14$ & $p=0.046$ \\
\hline MVPA & $144 \pm 66$ & $142 \pm 64$ & $186 \pm 69$ & $p<0.001$ \\
\hline \multicolumn{5}{|l|}{$\geq 60$ min MVPA per day } \\
\hline Meeting recommendations & $48 \%$ & $46 \%$ & $78 \%$ & \\
\hline
\end{tabular}

Values are mean \pm SD. P-value based on ANCOVA, adjusted for gender and age; *underweight children $(n=36)$ were excluded from analyses.

to gain further clarity regarding the influence of parental factors on health-related parameters such as MVPA or sedentary behaviour in primary school children.

In the present study more than two thirds of boys achieved at least $60 \mathrm{~min}$ of MVPA per day, whilst only $28 \%$ of girls met current recommendations. Similar results showing higher PA in boys compared to girls have previously been reported worldwide, e.g. in the United States amongst 6-19 year olds from the representative National Health and Nutrition Examination Survey (NHANES), and in the European Youth Heart Study (EYHS) examining a representative sample of different countries in Europe of 9 and 15-year-olds [28,37].

Despite the fact that PA levels have been shown to decline with age $[38,39]$, second grade children displayed higher activity levels then first graders in the current study. One reason may be that first graders have not yet adjusted to their new role as pupils or the increased sedentary time in the morning. In addition, sports club participation increases throughout childhood [14]. This was also shown in the present study where second graders spent more time in organised sports than first graders (data not shown), although these results were not statistically significant. In general, $75 \%$ of the children in the sub-sample in addition to the children in the main study participate in sports clubs. These results are consistent with the representative KiGGS study, where nearly threequarters of the children participate in sports clubs [14].

Furthermore, the study revealed that overweight/obese children spent more time in MVPA compared to normal weight children. This is in contrast to previous studies examining PA patterns between obese and normal weight children and adolescents aged 5 to 17 years [40-42]. One explanation of this finding might be the fact that the current study relied on both heart rate and accelerometry to determine PA rather than relying individually on heart rate or accelerometry. Overweight children might have displayed higher heart rates at light activities, which may in error have been classified as moderate. In this study however, using only heart rate data no differences in PA intensities between normal weight and overweight/obese children were found. There was no difference in average movement counts per day between normal weight and overweight/obese children either (data not shown). Other studies have also reported higher PA in overweight or obese children $[43,44]$ whilst some $[45,46]$ did not show any association between body weight and PA. In addition to that differences in measurement tools and 
discrepancies in sample size of overweight/obese children may have contributed to these ambiguous findings.

Limitations in the present study need to be considered when interpreting the findings. Even though PA was assessed objectively, the utilisation of METs to differentiate between PA intensity levels might have led to a misrepresentation of PA in the study population. Additionally, an interval of $15 \mathrm{sec}$ might be too long to accurately display children's activity patterns as, typically, they engage in very short, highly variable, unstructured movements $[4,47]$. Bailey et al. (1995) showed that periods of low and moderate intensities in children took an average of only $6 \mathrm{sec}$ and periods of vigorous intensity $3 \mathrm{sec}$ [47]. These short bouts may not have been adequately captured with a long interval in the present study. Even though children were selected state-wide from study schools involving different rural and urban settings and different social structures, there could have been a selection bias due to the fact that only pupils of teachers, who were interested in participating in a school-based intervention programme, were considered. Nevertheless, a national sample (KiGGS study) showed only a marginally higher prevalence of $15 \%$ overweight and obese children aged 7-10 years [48]. A comparable overweight prevalence of about 13\% was found in German children in the state of Baden-Württemberg at school entry [49]. The KiGGS study also showed a similar proportion of children with migration status, while the percentage of families with lower parental education was slightly higher compared to the present study $[50,51]$.

At this time, this study only extrapolated data of objectively assessed PA over a period of 24 hours to detect PA behaviour of primary school children has been used. Further research is necessary to get a close understanding of PA behaviour over the whole day with excluding sleeping time to get more information of different aspects during the day. Finally, it should be considered that data collection took place in autumn and weather may have influenced PA levels. However, it was not possible to determine the influence of weather on PA patterns of children. For further investigations this factor should be included in the analysis.

\section{Conclusions}

In summary, approximately just under half of primary school children in first and second grades meet current PA recommendations. Since sufficient PA in childhood contributes to an active lifestyle and other health-related parameters in later life, effective intervention programmes for the promotion of PA are required. The results of this study emphasise, in particular, low activity levels at the weekend. In order to achieve sufficient PA levels throughout the entire week, stronger parental and school involvement will be essential.

\section{Abbreviations}

BMI: Body mass index; BMIPCT: Body mass index percentile; $\mathrm{cm}$ : Centimeter; e.g.: For example; HR: Heart rate; IOTF: International Obesity Task Force; kg: Kilogram; $\mathrm{m}^{2}$ : Square meter; MET: Metabolic equivalent task; min: Minutes; MVPA: Moderate to vigorous physical activity; PA: Physical activity; PASW: Predictive analytics software; ref: Reference; SD: Standard deviation; sec: Seconds; vs.: Versus; yrs: Years.

\section{Competing interests}

The authors declare that they have no competing interests.

\section{Authors' contributions}

SK (corresponding author): conceptional work, data collection, data analyses, manuscript draft, manuscript editing, submission. SK: conceptional work, data collection, data analyses, manuscript revision. NF: data analyses, manuscript revision. CD: data analyses, manuscript revision. JD: conceptional work, data analyses, manuscript revision. TW: data collection, data analyses, manuscript revision. BK: conceptional work, manuscript revision. JMS: manuscript revision. All authors read and approved the final manuscript.

\section{Acknowledgements}

The intervention programme "Join the Healthy Boat - Primary School" as well as the evaluation, the "Baden-Württemberg study", have been financed by the Baden-Württemberg Stiftung, Stuttgart, Germany. The authors acknowledge and thank all members of the "Healthy Boat" intervention team including participating schools, teachers, parents and children of BadenWürttemberg, Germany. Other members of the Healthy Boat study group: Eva-Maria Friedemann, Verena Hundsdörfer, Dorothea Kesztyüs, Ileana Limberger, Prof. Dr. Rainer Muche, Dmytro Prokopchuk, Anja Schreiber, Prof. Dr. Dr. Olga Pollatos, Sabrina Sufeida, Meike Traub, Olivia Wartha.

\section{Author details}

'Sports- and Rehabilitation-Medicine, Research Group "Join the Healthy Boat - Primary School", Ulm University, Frauensteige 6 - House 58 / 33, 89075 Ulm, Germany. ${ }^{2}$ Institute of Epidemiology and Medical Biometry, Ulm University, Ulm, Germany.

Received: 3 March 2013 Accepted: 18 September 2013

Published: 28 September 2013

\section{References}

1. Strong WB, Malina RM, Blimkie CJ, Daniels SR, Dishman RK, Gutin B, Hergenroeder AC, Must A, Nixon PA, Pivarnik JM, Rowland T, Trost S, Trudeau F: Evidence based physical activity for school-age youth. J Pediatr 2005, 146:732-737.

2. Malina RM: Tracking of physical activity and physical fitness across the lifespan. Res Q Exerc Sport 1996, 67:S48-S57.

3. Pate RR, Baranowski T, Dowda M, Trost SG: Tracking of physical activity in young children. Med Sci Sports Exerc 1996, 28:92-96.

4. Boreham C, Riddoch C: The physical activity, fitness and health of children. J Sports Sci 2001, 19:915-929.

5. Telama R, Yang X, Viikari J, Valimaki I, Wanne O, Raitakari O: Physical activity from childhood to adulthood: a 21-year tracking study. Am J Prev Med 2005, 28:267-273.

6. Janz KF, Dawson JD, Mahoney LT: Tracking physical fitness and physical activity from childhood to adolescence: the muscatine study. Med Sci Sports Exerc 2000, 32:1250-1257.

7. Wang $Y$, Lobstein T: Worldwide trends in childhood overweight and obesity. Int J Pediatr Obes 2006, 1:11-25.

8. Biro FM, Wien M: Childhood obesity and adult morbidities. Am J Clin Nutr 2010, 91:1499S-1505S.

9. Weiss R, Dziura J, Burgert TS, Tamborlane WV, Taksali SE, Yeckel CW, Allen K, Lopes M, Savoye M, Morrison J, Sherwin RS, Caprio S: Obesity and the metabolic syndrome in children and adolescents. N Engl J Med 2004, 350:2362-2374.

10. Dollman J, Norton K, Norton L: Evidence for secular trends in children's physical activity behaviour. Br J Sports Med 2005, 39:892-897.

11. WHO: Global Recommendations on Physical Activity for Health. Geneva: World Health Organization; 2010. 
12. Ekelund $\mathrm{U}$, Tomkinson $\mathrm{G}$, Armstrong $\mathrm{N}$ : What proportion of youth are physically active? Measurement issues, levels and recent time trends. Br J Sports Med 2011, 45:859-865.

13. Krug S, Jekauc D, Poethko-Müller C, Woll A, Schlaud M: Relationship between physical activity and health in children and adolescents. Results of the German Health Interview and Examination Survey for Children and Adolescents (KiGGS) and the "Motorik-Modul" (MoMo). Bundesgesundheitsblatt Gesundheitsforschung Gesundheitsschutz 2012, 55:111-120

14. Lampert T, Mensink GB, Romahn N, Woll A: Physical activity among children and adolescents in Germany. Results of the German Health Interview and Examination Survey for Children and Adolescents (KiGGS). Bundesgesundheitsblatt Gesundheitsforschung Gesundheitsschutz 2007, 50:634-642.

15. HBSC-Team Deutschland: Studie Health Behaviour in School-aged Children Faktenblatt "Methodik der HBSC-Studie". Bielefeld: WHO Collaborating Centre for Child and Adolescent Health Promotion; 2011.

16. Sallis JF: Self-report measures of children's physical activity. J Sch Health 1991, 61:215-219.

17. Verloigne M, Van Lippevelde W, Maes L, Yildirim M, Chinapaw M, Manios Y, Androutsos O, Kovacs E, Bringolf-Isler B, Brug J, De Bourdeaudhuij I: Levels of physical activity and sedentary time among 10- to 12-year-old boys and girls across 5 European countries using accelerometers: an observational study within the ENERGY-project. Int J Behav Nutr Phys Act 2012, 9:34.

18. Dreyhaupt J, Koch B, Wirt T, Schreiber A, Brandstetter S, Kesztyüs D, Wartha O, Kobel S, Kettner S, Prokopchuk D, Hundsdörfer V, Klepsch M, Wiedom M Sufeida S, Fischbach N, Muche R, Seufert T, Steinacker J: Evaluation of a health promotion program in children: study protocol and design of the cluster-randomized Baden-Württemberg primary school study [DRKS-ID: DRKS00000494]. BMC Public Health 2012, 12:157.

19. Kromeyer-Hauschild K, Wabitsch M, Kunze D, Geller F, Geiß HC, Hesse V, Von Hippel A, Jaeger U, Johnsen D, Korte W, Menner K, Müller G, Müller JM, Niemann-Pilatus A, Remer T, Schaefer F, Wittchen HU, Zabransky S, Zellner K, Ziegler A, Hebebrand J: Percentiles of body mass index in children and adolescents evaluated from different regional German studies. Monatsschr Kinderheilkd 2001, 149:807-818.

20. Cole TJ, Bellizzi MC, Flegal KM, Dietz WH: Establishing a standard definition for child overweight and obesity worldwide: international survey. BM 2000, 320:1240-1243.

21. Brage S, Brage N, Franks PW, Ekelund U, Wareham NJ: Reliability and validity of the combined heart rate and movement sensor Actiheart. Eur J Clin Nutr 2005, 59:561-570.

22. Corder K, Brage S, Wareham NJ, Ekelund U: Comparison of PAEE from combined and separate heart rate and movement models in children. Med Sci Sports Exerc 2005, 37:1761-1767.

23. Corder K, Brage S, Mattocks C, Ness A, Riddoch C, Wareham NJ, Ekelund U: Comparison of two methods to assess PAEE during six activities in children. Med Sci Sports Exerc 2007, 39:2180-2188.

24. Pate RR, Pratt M, Blair SN, Haskell WL, Macera CA, Bouchard C, Buchner D, Ettinger W, Heath GW, King AC, Kriska A, Leon AS, Marcus BH, Morris J, Paffenbarger RS, Patrick K, Pollock ML, Rippe JM, Sallis J, Wilmore JH: Physical activity and public health. A recommendation from the Centers for Disease Control and Prevention and the American College of Sports Medicine. JAMA 1995, 273:402-407.

25. Trost SG, Pate RR, Freedson PS, Sallis JF, Taylor WC: Using objective physical activity measures with youth: how many days of monitoring are needed? Med Sci Sports Exerc 2000, 32:426-431.

26. Brauns H, Scherer S, Steinmann S: The CASMIN educational classification in international comparative research. In Advances in Cross-National Comparison: a European Working Book for Demographic and Socio-Economic Variables. Edited by Hoffmeyer-Zlotnik JHP, Wolf C. New York: Kluwer Academic / Plenum Publishers; 2003:221-244.

27. Aznar S, Naylor PJ, Silva P, Pérez M, Angulo T, Laguna M, Lara MT, López-Chicharro J: Patterns of physical activity in Spanish children: a descriptive pilot study. Child Care Health Dev 2011, 37:322-328.

28. Riddoch CJ, Bo Andersen L, Wedderkopp N, Harro M, Klasson-Heggebo L, Sardinha LB, Cooper AR, Ekelund U: Physical activity levels and patterns of 9- and 15-yr-old European children. Med Sci Sports Exerc 2004, 36:86-92
29. Beets MW, Bornstein D, Dowda M, Pate RR: Compliance with national guidelines for physical activity in U.S. Preschoolers: measurement and interpretation. Pediatrics 2011, 127:658-664

30. Vorwerg Y, Petroff D, Kiess W, Bluher S: Physical activity in 3-6 year old children measured by SenseWear Pro(R): direct accelerometry in the course of the week and relation to weight status, media consumption, and socioeconomic factors. PLOS One 2013, 8:e60619.

31. Nilsson A, Anderssen SA, Andersen LB, Froberg K, Riddoch C, Sardinha LB, Ekelund $U$ : Between- and within-day variability in physical activity and inactivity in 9- and 15-year-old European children. Scand J Med Sci Sports 2009, 19:10-18.

32. Comte M, Hobin E, Majumdar SR, Plotnikoff RC, Ball GD, McGavock J: Patterns of weekday and weekend physical activity in youth in 2 Canadian provinces. Appl Physiol Nutr Metab 2013, 38:115-119.

33. Fuemmeler B, Anderson C, Masse L: Parent-child relationship of directly measured physical activity. Int J Behav Nutr Phys Act 2011, 8:1-9.

34. Sigmund E, Turonová K, Sigmundová D, Pridalová M: The effect of parents' physical activity and inactivity on their children's physical activity and sitting. Acta Univ Palacki Olomuc, Gymn 2008, 38:17-23.

35. Hennessy E, Hughes S, Goldberg J, Hyatt R, Economos C: Parent-child interactions and objectively measured child physical activity: a cross-sectional study. Int J Behav Nutr Phys Act 2010, 7:1-14.

36. Cleland V, Crawford D, Baur LA, Hume C, Timperio A, Salmon J: A prospective examination of children's time spent outdoors, objectively measured physical activity and overweight. Int J Obes 2008, 32:1685-1693.

37. Gortmaker SL, Lee R, Cradock AL, Sobol AM, Duncan DT, Wang YC: Disparities in youth physical activity in the United States: 2003-2006. Med Sci Sports Exerc 2012, 44:888-893.

38. Dumith SC, Gigante DP, Domingues MR, Kohl HW: Physical activity change during adolescence: a systematic review and a pooled analysis. Int J Epidemiol 2011, 40:685-698.

39. Sallis JF: Age-related decline in physical activity: a synthesis of human and animal studies. Med Sci Sports Exerc 2000, 32:1598-1600.

40. Hughes AR, Henderson A, Ortiz-Rodriguez V, Artinou ML, Reilly JJ: Habitual physical activity and sedentary behaviour in a clinical sample of obese children. Int J Obes 2006, 30:1494-1500.

41. Page A, Cooper AR, Stamatakis E, Foster LJ, Crowne EC, Sabin M, Shield JPH: Physical activity patterns in nonobese and obese children assessed using minute-by-minute accelerometry. Int J Obes Relat Metab Disord 2005, 29:1070-1076

42. Chung AE, Skinner AC, Steiner MJ, Perrin EM: Physical activity and BMI in a nationally representative sample of children and adolescents. Clin Pediatr Phila 2012, 51:122-129.

43. Gazzaniga JM, Burns TL: Relationship between diet composition and body fatness, with adjustment for resting energy expenditure and physical activity, in preadolescent children. Am J Clin Nutr 1993, 58:21-28.

44. Romanella NE, Wakat DK, Loyd BH, Kelly LE: Physical activity and attitudes in lean and obese children and their mothers. Int J Obes 1991, 15:407-414

45. Al-Hazzaa HM, Sulaiman MA, Al-Matar AJ, Al-Mobaireek KF: Cardiorespiratory fitness, physical activity patterns and coronary risk factors in preadolescent boys. Int J Sports Med 1994, 15:267-272.

46. Goran MI, Hunter G, Nagy TR, Johnson R: Physical activity related energy expenditure and fat mass in young children. Int J Obes Relat Metab Disord 1997, 21:171-178.

47. Bailey RC, Olson J, Pepper SL, Porszasz J, Barstow TJ, Cooper DM: The level and tempo of children's physical activities: an observational study. Med Sci Sports Exerc 1995, 27:1033-1041.

48. Kurth BM, Schaffrath Rosario A: Overweight and obesity in children and adolescents in Germany. Bundesgesundheitsblatt Gesundheitsforschung Gesundheitsschutz 2010, 53:643-652.

49. Moss A, Wabitsch M, Kromeyer-Hauschild K, Reinehr T, Kurth BM: Prevalence of overweight and adiposity in German school children Bundesgesundheitsblatt Gesundheitsforschung Gesundheitsschutz 2007, 50:1424-1431.

50. Schenk L, Ellert U, Neuhauser H: Children and adolescents in Germany with a migration background. Methodical aspects in the German Health Interview and Examination Survey for Children and Adolescents (KiGGS). Bundesgesundheitsblatt Gesundheitsforschung Gesundheitsschutz 2007, 50:590-599. 
51. Lange M, Kamtsiuris $P$, Lange $C$, Schaffrath Rosario A, Stolzenberg H, Lampert T: Sociodemographic characteristics in the German Health Interview and Examination Survey for Children and Adolescents (KiGGS) - operationalisation and public health significance, taking as an example the assessment of general state of health.

Bundesgesundheitsblatt Gesundheitsforschung Gesundheitsschutz 2007. 50:578-589.

doi:10.1186/1471-2458-13-895

Cite this article as: Kettner et al:: Objectively determined physical

activity levels of primary school children in south-west Germany. BMC Public Health 2013 13:895.

\section{Submit your next manuscript to BioMed Central and take full advantage of:}

- Convenient online submission

- Thorough peer review

- No space constraints or color figure charges

- Immediate publication on acceptance

- Inclusion in PubMed, CAS, Scopus and Google Scholar

- Research which is freely available for redistribution 